\title{
Vulpinic Acid as a Natural Compound Inhibits the Proliferation of Metastatic Prostate Cancer Cell by Inducing Apoptosis
}

Demet Cansaran Duman ( $\sim$ dcansaran@yahoo.com )

Ankara Universitesi

Gamze Guney Eskiler

Sakarya Universitesi

Betül Çolak

Ankara Universitesi

Elif Sozen Kucukkara

Sakarya Universitesi

\section{Research Article}

Keywords: Prostate cancer, vulpinic acid, apoptosis, lichens

Posted Date: May 17th, 2021

DOI: https://doi.org/10.21203/rs.3.rs-515712/v1

License: (c) (i) This work is licensed under a Creative Commons Attribution 4.0 International License. Read Full License

Version of Record: A version of this preprint was published at Molecular Biology Reports on July 30th, 2021. See the published version at https://doi.org/10.1007/s11033-021-06605-5. 


\section{Abstract}

Lichen secondary metabolites have drawn considerable attention in recent years due to limitations of current treatment options. Vulpinic acid (VA) obtained from Letharia vulpina lichen species exerts a remarkable cytotoxic effect on different cancer types. However, the therapeutic efficacy of VA in metastatic prostate cancer ( $\mathrm{mPC}$ ) cells has not been investigated. In the present study, we aimed to identify VA-mediated cytotoxicity in PC-3 mPC cells compared with control cells. After identification of the cytotoxic concentrations of VA, VA induced apoptosis was analyzed by Annexin V, cell cycle, acridine orange and propidium iodide staining and RT-PCR analysis. Our findings showed that VA significantly decreased the viability of PC-3 cells $(p<0.01)$ and caused a considerable early apoptotic effect through G0/G1 arrest, nuclear bleebing and the activation of particularly initiator caspases. Therefore, VA may be a potential treatment option for mPC patients. However, the underlying molecular mechanisms of VAinduced apoptosis with advanced analysis should be further performed.

\section{Introduction}

Cancer has been identified as an important cause of death worldwide [1]. The cancer incidence is expected to rise to over 20 million new cases by 2025 [2]. Prostate cancer is the most diagnosed in men in Europe and is the third cancer type among cancer deaths [2]. In the early stages, hormone sensitive prostate cancer patients can be treated with surgery, radiotherapy and hormonal therapy. However, castration resistance is observed in nearly $10-20 \%$ of prostate cancer patients within 5 years and $84 \%$ of patients develop metastasis at the time of castration resistance [3, 4]. Docetaxel is used as the treatment option for metastatic castration resistant prostate cancer patients [5]. However, drug-resistance develops overtime against chemotherapeutics used in prostate cancer patients. Therefore, future studies should focus on researching new, less toxic and stronger drug candidate molecules that affect cancer cells.

In recent studies, the effectiveness of natural products on cancer cells has been determined due to their abundant and excessive extraction from nature and non-toxic effects [6, 7]. Within the scope of drug development studies, 175 anti-cancer drugs were developed between 1940 and 2010. Approximately 50\% of the anti-cancer drugs developed are of natural origin or derived from natural products $[8,9]$. Natural products can be obtained from plants, animals, marine organisms, lichens, fungi and microorganisms [10]. Plants synthesize many bioactive secondary metabolites such as alkaloids, flavonoids, phenolics, terpenoids, steroids, tannins, and essential oils [11]. Lichens are a powerful biological organism for the synthesis of many economically, pharmaceutically and strategically important bioactive secondary metabolites.

Vulpinic acid (VA) is one of the secondary metabolites of lichen. The chemical formula of VA is $\mathrm{C}_{19} \mathrm{H}_{14} \mathrm{O}_{5}$ and VA has antimicrobial, antifungal and anti-cancer activity. The anti-proliferative effect of VA isolated from Letharia vulpina lichen species on HepG2, NS2OY and HUVEC cells was determined [12]. In our previous study, the anti-proliferative effect of VA on different breast cancer cells (MCF-7, MDA-MB-231, BT-474, SK-BR-3) and epithelial cells (MCF-12A) was revealed [13]. In the study, the specific proliferation 
suppressing effect of VA on breast cancer cells without cytotoxic effect on non-cancerous breast epithelial cell was determined. Moreover, it has been determined that VA induces apoptosis [13]. With a similar approach, the anti-cancer activity of VA on different cancer cell lines (CaCo2, HepG2, Hep2C, RD, Wehi) has also been determined in another previous study [14]. The results obtained showed that VA could be evaluated as a cancer-focused promising drug candidate molecule.

It was aimed to develop VA-mediated new approaches for the treatment and prevention of metastatic prostate cancer, one of the aggressive cancer types, and to elucidate the apoptosis mechanism after treatment with VA application. Herein, we show that VA selectively kills prostate cancer cells without significant side effects on noncancerous epithelial cells and we also provide evidence suggesting the VA induces apoptosis through extrinsic pathways via induction of Caspases and Bax.

\section{Materials And Methods Cell culture}

The human metastatic prostate cancer cells (PC-3) and human umbilical vein endothelial cells (HUVEC) were obtained from the American Type Culture Collection (ATCC, Rockville, USA). The PC-3 cells were cultured in Roswell Park Memorial Institute-1640 (RPMI-1640, Gibco, USA) cell culture medium and HUVEC cells were seeded in Dulbecco's modified eagle medium (DMEM, Gibco, USA) supplemented with $10 \%$ fetal bovine serum (FBS, Gibco, USA) and 1\% penicillin/streptomycin (Gibco, Invitrogen, USA). The cells were incubated in a humidified incubator at $37^{\circ} \mathrm{C}$ with $5 \% \mathrm{CO}_{2}$.

\section{xCELLigence assay}

PC-3 and HUVEC cells ( $1 \times 10^{4}$ cells/well) were cultured in e-plates (ACEA Biosciences Inc., San Diego, CA, USA) and placed into the RTCA xCELLigence instrument (Roche Diagnostics, Mannheim, Germany). The cells were exposed to different concentrations of VA $(1.56,3.12,6.25,12.5,25,50$ and $100 \mu \mathrm{M})$ and cellular impedance was measured in intervals of $15 \mathrm{~min}$ for $96 \mathrm{~h}$. The commonly known anticancer drug Cabazitaxel (1, 5 and $10 \mathrm{mg}$ ) was used to compare the anti-proliferative effect of VA. The time-dependent cell index $(\mathrm{Cl})$ graph was analyzed by xCELLigence RTCA S16 Instrument (xCELLigence RTCA, Roche, Germany). According to the obtained results, the value of $I C_{25}, I C_{50}$ and $I C_{75}$ in the most effective exposure time was calculated and used for further analysis.

\section{Annexin V Analysis}

The cells $\left(1 \times 10^{5}\right.$ cells/well) were treated with $I_{25}, I C_{50}$ and IC $\mathrm{C}_{75}$ dose of VA for $48 \mathrm{~h}$ in 12-well plates. Afterward, the cells were harvested and resuspended with the Muse ${ }^{\mathrm{TM}}$ Annexin $\mathrm{V}$ and Dead Cell reagent. 
The stained cells were analyzed using the Muse ${ }^{\mathrm{TM}}$ Cell Analyzer (Millipore, Germany) and the cells were classified into four groups: live, early apoptotic, late apoptotic and necrosis.

\section{Cell Cycle}

The cells $\left(5 \times 10^{5}\right.$ cells/well) were exposed to $\mathrm{IC}_{25}, \mathrm{IC}_{50}$ and $\mathrm{IC}_{75}$ dose of VA for $48 \mathrm{~h}$. Following incubation, the cells were fixed in $70 \%$ ethyl alcohol $(\mathrm{EtOH})$ for $3 \mathrm{~h}$. Afterward, Muse ${ }^{\mathrm{TM}}$ Cell Cycle Kit (Merck Millipore, Germany) was added into each tube and incubated for $30 \mathrm{~min}$ in the dark and analyzed by the Muse $\mathrm{TM}^{\mathrm{TM}}$ Cell Analyzer.

\section{Acridine Orange (AO) and Propidium lodide (PI) Staining}

The cells $\left(2 \times 10^{5}\right.$ cells/well) were treated with $\mathrm{IC}_{25}, \mathrm{IC}_{50}$ and $\mathrm{IC}_{75}$ dose of VA for $48 \mathrm{~h}$. After incubation, the cells were fixed with $4 \%$ paraformaldehyde for $30 \mathrm{~min}$ and AO/PI staining was added into each well and incubated for 30 min in dark conditions. The cells were examined with EVOS FL Cell Imaging System (Thermo Fisher Scientific, USA).

\section{Real-time (RT) PCR analysis}

PC-3 cells $\left(5 \times 10^{5}\right.$ cells/well) were cultured in 6-well plates and then treated with $\mathrm{IC}_{50}$ dose of VA for $48 \mathrm{~h}$. RNA quantity/quality was measured with a NanoDrop 1000 ND-Spectrophotometer (Thermo Fisher Scientific, Waltham, USA). One microgram of the total RNA from each sample was converted to cDNA using Transcriptor High Fidelity cDNA Synthesis Kit (miScript ${ }^{\circledR}$ II RT Kit, Qiagen). The level of gene expression was determined by Human Apoptosis Primer Library (Real Time Primers, US) by using LightCycler 480 PCR (Roche, Germany). GAPDH is used as a housekeeping gene which is used for normalization. All qRT-PCR reactions were performed in three independent biological triplicates.

\section{Statistical analysis}

The target gene transcripts was normalized to GAPDH and set relative to control samples according to the $2^{-\triangle \Delta C T}$ method [15]. The result of gene expression fold change was applied one-way ANOVA. The Fisher's significance level $(p \otimes 0.05)$ was performed. Graphpad Prism 8.0 software was used to represent data on the graph.

\section{Cell culture}

The human metastatic prostate cancer cells (PC-3) and human umbilical vein endothelial cells (HUVEC) were obtained from the American Type Culture Collection (ATCC, Rockville, USA). The PC-3 cells were 
cultured in Roswell Park Memorial Institute-1640 (RPMI-1640, Gibco, USA) cell culture medium and HUVEC cells were seeded in Dulbecco's modified eagle medium (DMEM, Gibco, USA) supplemented with $10 \%$ fetal bovine serum (FBS, Gibco, USA) and 1\% penicillin/streptomycin (Gibco, Invitrogen, USA). The cells were incubated in a humidified incubator at $37^{\circ} \mathrm{C}$ with $5 \% \mathrm{CO}_{2}$.

\section{xCELLigence assay}

PC-3 and HUVEC cells ( $1 \times 10^{4}$ cells/well) were cultured in e-plates (ACEA Biosciences Inc., San Diego, CA, USA) and placed into the RTCA xCELLigence instrument (Roche Diagnostics, Mannheim, Germany). The cells were exposed to different concentrations of VA $(1.56,3.12,6.25,12.5,25,50$ and $100 \mu \mathrm{M})$ and cellular impedance was measured in intervals of $15 \mathrm{~min}$ for $96 \mathrm{~h}$. The commonly known anticancer drug Cabazitaxel (1, 5 and $10 \mathrm{mg}$ ) was used to compare the anti-proliferative effect of VA. The time-dependent cell index $(\mathrm{Cl})$ graph was analyzed by xCELLigence RTCA S16 Instrument (xCELLigence RTCA, Roche, Germany). According to the obtained results, the value of $\mathrm{IC}_{25}, \mathrm{IC}_{50}$ and $I \mathrm{IC}_{75}$ in the most effective exposure time was calculated and used for further analysis.

\section{Annexin V Analysis}

The cells $\left(1 \times 10^{5}\right.$ cells/well) were treated with $\mathrm{IC}_{25}, \mathrm{IC}_{50}$ and $\mathrm{IC}_{75}$ dose of VA for $48 \mathrm{~h}$ in 12 -well plates. Afterward, the cells were harvested and resuspended with the Muse ${ }^{\mathrm{TM}}$ Annexin $\mathrm{V}$ and Dead Cell reagent. The stained cells were analyzed using the Muse ${ }^{\mathrm{TM}}$ Cell Analyzer (Millipore, Germany) and the cells were classified into four groups: live, early apoptotic, late apoptotic and necrosis.

\section{Cell Cycle}

The cells $\left(5 \times 10^{5}\right.$ cells/well) were exposed to $\mathrm{IC}_{25}, \mathrm{IC}_{50}$ and $\mathrm{IC}_{75}$ dose of VA for $48 \mathrm{~h}$. Following incubation, the cells were fixed in $70 \%$ ethyl alcohol (EtOH) for $3 \mathrm{~h}$. Afterward, Muse ${ }^{\mathrm{TM}}$ Cell Cycle Kit (Merck Millipore, Germany) was added into each tube and incubated for $30 \mathrm{~min}$ in the dark and analyzed by the Muse $\mathrm{TM}^{\mathrm{TM}}$ Cell Analyzer.

\section{Acridine Orange (A0) and Propidium lodide (PI) Staining}

The cells $\left(2 \times 10^{5}\right.$ cells/well) were treated with $\mathrm{IC}_{25}, \mathrm{IC}_{50}$ and $\mathrm{IC}_{75}$ dose of VA for $48 \mathrm{~h}$. After incubation, the cells were fixed with $4 \%$ paraformaldehyde for $30 \mathrm{~min}$ and $\mathrm{AO} / \mathrm{PI}$ staining was added into each well and incubated for 30 min in dark conditions. The cells were examined with EVOS FL Cell Imaging System (Thermo Fisher Scientific, USA). 


\section{Real-time (RT) PCR analysis}

PC-3 cells $\left(5 \times 10^{5}\right.$ cells/well) were cultured in 6-well plates and then treated with $\mathrm{IC}_{50}$ dose of VA for $48 \mathrm{~h}$. RNA quantity/quality was measured with a NanoDrop 1000 ND-Spectrophotometer (Thermo Fisher Scientific, Waltham, USA). One microgram of the total RNA from each sample was converted to cDNA using Transcriptor High Fidelity cDNA Synthesis Kit (miScript® II RT Kit, Qiagen). The level of gene expression was determined by Human Apoptosis Primer Library (Real Time Primers, US) by using LightCycler 480 PCR (Roche, Germany). GAPDH is used as a housekeeping gene which is used for normalization. All qRT-PCR reactions were performed in three independent biological triplicates.

\section{Statistical analysis}

The target gene transcripts was normalized to GAPDH and set relative to control samples according to the $2^{-\triangle \Delta C T}$ method [15]. The result of gene expression fold change was applied one-way ANOVA. The Fisher's significance level ( $\mathrm{p} \otimes 0.05$ ) was performed. Graphpad Prism 8.0 software was used to represent data on the graph.

\section{Results}

\section{VA decreased PC-3 Cells' Viability}

The effect of VA on the viability of the cells was tested by the RTCA xCELLigence system for the first time in this study. RTCA xCELLigence system was enabled to measure with electronic impedance for determining detailed monitoring the cells continuously and quantitatively. The $\mathrm{IC}_{50}$ value of VA is calculated based on $\mathrm{Cl}$ at every measuring point of study. The obtained $\mathrm{IC}_{50}$ value of VA by using the RTCA xCELLigence system was $27 \mu \mathrm{M}$ for $48 \mathrm{~h}$ obtained from the sigmoidal dose-response formula in software (Fig. 1A). Cabazitaxel was $10.9 \mu \mathrm{M}$ for $48 \mathrm{~h}$ on PC-3 cell (Fig. 1B). Additionally, HUVEC cells were treated with all examined concentrations of VA. All concentrations of VA increased compared with control in HUVEC non-cancerous cell by using the RTCA system (Fig. 1C). It was showed that VA inhibited the proliferation of PC-3 prostate cancer cell. However, the less concentrations of VA did not exert cytotoxic effect on non-cancerous epithelial cell lines (HUVEC). Therefore, VA could be a better therapeutic option than cabazitaxel in terms of dose concentration.

\section{Evaluation of VA induced apoptotic cell death in metastatic prostate cancer}

The induction of VA-mediated apoptosis in castration resistant metastatic prostate cancer cells was assessed by Annexin V and cell cycle analysis (Fig. 2 and 3). Our findings demonstrated that VA caused a considerable increase in the early apoptotic cell death in PC-3 cells dose-dependently (Fig. 2, p<0.01). 
Following treatment with the $\mathrm{IC}_{25}, \mathrm{IC}_{50}$ and $\mathrm{IC}_{75}$ dose of $\mathrm{VA}$, the total apoptotic death rate increased from $2.6 \%$ to $31.9 \%, 48.9 \%$ and $60.7 \%$, respectively in PC-3 cells. Furthermore, the total of apoptotic cell death was detected as $15.1 \%, 25.1 \%$ and $34.7 \%$ at the concentration of $\mathrm{IC}_{25}, \mathrm{IC}_{50}$ and $\mathrm{IC}_{75}$, respectively in HUVEC cells in Fig 2.

VA-mediated cell cycle arrest was also analyzed in our study. As shown in Fig.3, VA treatment induced G0/G1 arrest in both PC-3 and HUVEC cells. In PC-3 cells, the accumulation of cells in G0/G1 arrest significantly increased to $62.8 \%, 68.8 \%$ and $74.3 \%$, \% at the concentration of $\mathrm{IC}_{25}, \mathrm{IC}_{50}$ and $\mathrm{IC}_{75}$, respectively $(p<0.01)$. On the other hand, the population of cells in $\mathrm{G} 0 / \mathrm{G} 1$ phase was remarkably increased to $64.6 \%, 70.6 \%$ and $79.4 \%$, respectively in VA treated HUVEC cells compared to control cells (51.5\%). Therefore, VA treatment could result in significant apoptotic cell death through the induction of G0/G1 phase arrest in metastatic prostate cancer cells.

\section{Observation of VA induced apoptotic cell death by AO/PI staining}

The results from AO/PI staining revealed that VA treatment changed particularly nuclear morphology in metastatic prostate cancer cells (Fig. 4). In PC-3 cells, condensation of DNA and markedly the formation of nuclear bleb through degradation of nuclear lamina were observed dose-dependently compared with control cells. Similar nuclear damages were also observed in HUVEC cells after exposure to the increased concentration of the VA.

\section{VA changed the expression of target genes}

We used real-time PCR using Human Apoptosis Primer Library for determining some apoptotic gene expression patterns after applying of VA in PC-3 cell. In RT-PCR analysis, the $\mathrm{IC}_{50}$ value of VA was selected as an optimum concentration. The target gene expression is demonstrated in Fig. 5. In the PC-3 cell, VA significantly increased CASP1 (pष0.05), CASP4 (pष0.001), CASP5 (pष0.01), CASP2, CASP8 (pष0.05),

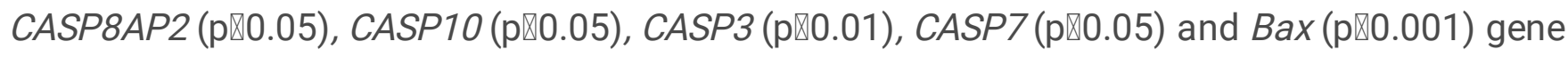
expression compared with the control. $B C l-2$ gene expression was significantly down-regulated after treatment with VA in PC-3 cells compared with control.

\section{Discussion}

Herein, we investigated the potential therapeutic effects of VA on castration resistant metastatic prostate cancer cells. Our findings showed that VA treatment could result in apoptotic cell death through G0/G1 arrest, nuclear blebbing and particularly the activation of apoptotic cell death initiators (caspase 1, caspase 2 and caspase 8) and executioner (caspase 3) as well as the over-expression of Bax mRNA level. 
Secondary metabolites of lichens have been great attention in preclinical cancer studies due to their antiinflammatory, anti-proliferative, and anti-neoplastic effects $[12,16,17]$. After isolation of several seconder metabolites such as usnic acid, atronarin, gyrophoric acid, barbaric acid, hypostictic acid and vulpinic acid (VA) obtained from different lichens and/or extraction of lichens, their potential anti-cancer effects have been determined in various types of cancer cell lines $[12,17,18]$. Among them, there is a limited number of a study investigating the potential therapeutic efficacy of VA in cancer cell $[13,14,19,20]$. The study of KIlıc et al (2018) state that VA exhibits significant cytotoxicity in breast cancer cell lines (MCF-7, MDA-MB-231, BT-474, SK-BR-3) compared to MCF-12A control cells and triggers apoptosis in the cells [13]. Furthermore, the expression level of $p 53$ increased to 14-fold in SK-BR-3 cells compared to control cells following treatment with $\mathrm{IC}_{50}$ concentration of VA [13]. In another study, the cytotoxic effects of VA on CaCo2, HepG2, Hep2C, RD, Wehi and normal cells (Vero and L929) have been assessed at a molecular level. Their findings show that $\mathrm{IC}_{50}$ dose of VA is different in terms of the features of cells and the expression level of Bax is significantly increased in all cell lines due to its apoptotic effects [14]. The study of Kim et al.(2017) state that the isolated VA from Pulveroboletus ravenelii as an edible mushroom mediates the cytotoxic effects of $P$. ravenelli on different human cancer cells including lung adenocarcinoma, pancreatic ductal adenocarcinoma and hepatocellular carcinoma cell lines through the induction of apoptosis [20]. Furthermore, the anti-angiogenic and antiproliferative effects of VA on HEPG2, NS2oY and HUVEC cells compared with usnic acid (UA) have been determined. According to their findings, both UA and VA had more cytotoxic activity in cancer cell lines than normal cell line. However, VA exerts more anti-angiogenic activity than UA [20]. In the present study, we investigated VA-mediated cytotoxicity in castration resistant metastatic prostate cancer cells due to highly aggressive behavior including metastatic and angiogenic potential of prostate cancer cells, for the first time. Our findings demonstrated that VA significantly decreased the viability of PC-3 cells $(p<0.01)$ and induced early apoptosis in dose-dependently through G0/G1 arrest and the formation of nuclear bleb with less toxicity in HUVEC normal cells. Moreover, considerably higher expression levels of pro-apoptotic markers were analyzed in PC-3 cells after treatment with $\mathrm{IC}_{50}$ value of VA $(\mathrm{p}<0.05)$. Interestingly, a nearly 25 -fold increase in the expression of Caspase- 1 level was determined in PC-3 cells treated with VA compared to other apoptotic markers. The caspase 3 and 9 protein levels are low in PC-3, DU-145, TSU-Pr1m and LNCaP cells, while lower expression of caspase- 1 is observed in Du-145 and LNCaP cells [21]. Therefore, the loss of caspase- 1 is an important step in prostate tumorigenesis. Additionally, the over-expression of Caspase- 1 induces TGF- $\beta$ and Fas-mediated apoptosis and enhances radiosensitivity in prostate cancer cells [22]. On the other hand, the proteolytic activity of caspase- 1 is mediated by inflammasome and some interleukins (IL-1 $\beta$ and IL-18) are substrates of caspase 1 [23]. Therefore, a higher activity of caspase- 1 can be associated with the apoptotic and anti-inflammatory effects of VA on prostate cancer cells in our study. However, further investigations should be performed to elucidate the underlying mechanisms of the VA induced caspase- 1 activity in the tumor microenvironment. Additionally, the expression levels of Caspase 2, 3, 5, 8 as well as Bax were higher in VA treated cells compared to control cells due to its apoptotic effects via the down-regulation of $B c /-2$ level. The study of Taghiyev et al. (2011), the activation of Caspase-2 mediates AR activity in LNCaP prostate cancer cells [24]. Briefly, our findings showed that VA regulated the activation of initiators caspase expression levels and extrinsic 
apoptotic mechanism. However, the underlying molecular mechanism of VA induced apoptosis and its associated signaling pathways as well as the function of caspase activation need to further investigations at a particularly the protein level.

\section{Conclusion}

In our study, VA exhibits significant anti-proliferative and apoptotic effects on castration resistant metastatic prostate cancer cells through the activation of particularly initiator caspases and G0/G1 arrest. Therefore, VA could be a new therapeutic target as a seconder metabolite for effective treatment in advanced prostate cancer. However, further preclinical studies are needed to investigate the efficacy of VA in different types of prostate cancer cells at a molecular level and to determine the potential combined effects of VA with different chemotherapy drugs.

\section{Declarations}

\section{Acknowledgements}

This research was supported by the research grants from Scientific and Technological Research Council of Turkey (TUBITAK, Project no. 216S583).

\section{Authorship contribution}

DCD and GGE conceived and designed the analysis, contributed to the interpretation of the results and wrote manuscript. EEK and BC contributed to analysis tools.

\section{Declaration of competing interest}

The authors declare that they have no known competing financial interests or personal relationships that could have appeared to influence the work reported in this paper.

\section{References}

1. Bhanot A, Sharma R, Noolvi MN (2011) Natural sources as potential anti-cancer agents: A review. International Journal of Phytomedicine 3:09-26.

2. Ferlay J, Soerjomataram I, Dikshit R et al (2015) Cancer incidence and mortality worldwide: sources, methods and major patterns in GLOBOCAN 2012. International journal of cancer 136(5): E359-86.

3. Ferlay J, Steliarova-Foucher E, Lortet-Tieulent $J$ et al. (2013) Cancer incidence and mortality patterns in Europe: estimates for 40 countries in 2012. European Journal of Cancer 49(6): 1374-1403.

4. Labriola MK, Atiq S, Hirshman N et al. (2020) Management of men with metastatic castrationresistant prostate cancer following potent androgen receptor inhibition: a review of novel 
investigational therapies. Prostate Cancer and Prostatic Diseases 1-9.

5. Naponelli V, Modernelli A, Bettuzzi S et al. (2015) Roles of Autophagy Induced by Natural Compounds in Prostate Cancer. BioMed Research International 1-14.

6. Deng LJ, Qi M, Li N et al. (2020) Natural products and their derivatives: Promising modulators of tumor immunotherapy. J Leukoc Biol 108(2): 493-508.

7. Gou L, Yue GG, Puno PT et al. (2021) A review on the relationship of mast cells and macrophages in breast cancer - Can herbs or natural products facilitate their anti-tumor effects? Pharmacol Research 164: 105321.

8. Gurnani N, Mehta D, Gupta M et al. (2014) Natural products: Source of potential drugs. African Journal of Basic \& Applied Sciences 6 :171-86.S.

9. Mushtaq S, Abbasi BH, Uzair B et al. (2018) Natural Products As Reservoirs of Novel Therapeutic Agents. EXCLI Journal 17: 420-451

10. Jabeen S, Hanifa MS, Khan MM et al (2014) Natural products sources and their active compounds on disease prevention: A review. International Journal of Chemical and Biochemical Sciences 6: 76 83.

11. Alamgir NM. (2018) Biotechnology, In Vitro Production of Natural Bioactive Compounds, Herbal Preparation, and Disease Management (Treatment and Prevention). In: Therapeutic Use of Medicinal Plants and their Extracts: Volume 2, Progress in Drug Research 74, Springer International Publishing $A G$, part of Springer Nature.

12. Solárová Z, Liskova A, Samec M, Kubatka P, Büsselberg D, Solár P (2020) Anticancer Potential of Lichens' Secondary Metabolites. Biomolecules 10(1): 87.

13. Kılıç N, Aras S, Cansaran-Duman D (2019) Determination of Vulpinic Acid Effect on Apoptosis and mRNA Expression Levels in Breast Cancer Cell Lines ACAMC 18: 2032-2041.

14. Kılıc N, Derici MK, Buyuk I et al. (2018) Evaluation of in vitro Anticancer Activity of Vulpinic Acid and its Apoptotic Potential Using Gene Expression and Protein Analysis. IJPER 52: 626-634.

15. Livak KJ, Schmittgen TD (2001) Analysis of relative gene expression data using real-time quantitative PCR and the 2- $\triangle \mathrm{CT}$ method, Methods 25: 402-408.

16. Nguyen TTH, Dinh MH, Chi HT et al. (2019) Antioxidant and cytotoxic activity of lichens collected from Bidoup Nui Ba National Park, Vietnam. Res. Chem. Intermed 45: 33-49.

17. Stanojković T (2019) Investigations of Lichen Secondary Metabolites with Potential Anticancer Activity, In: Ranković B. (eds) Lichen Secondary Metabolites. Springer, Cham: 155-174.

18. Goga M, Elečko J, Marcinčinová M et al. (2020) Lichen metabolites: an overview of some secondary metabolites and their biological potential, Co-evolution of secondary metabolites, In: Merillon JM., Ramawat K. (eds) Co-Evolution of Secondary Metabolites. Reference Series in Phytochemistry. Springer, Cham 175-209S.

19. Kim S, So HM, Roh HS et al. (2017) Vulpinic acid contributes to the cytotoxicity of Pulveroboletus ravenelii to human cancer cells by inducing apoptosis. RSC advances 7(56): 35297-35304. 
20. Koparal AT (2015) Anti-angiogenic and antiproliferative properties of the lichen substances (-)-usnic acid and vulpinic acid. Zeitschrift für Naturforschung C 70(5-6): 159-164.

21. Winter RN, Kramer A, Borkowski A et al. (2001) Loss of caspase-1 and caspase-3 protein expression in human prostate cancer. Cancer research 61(3): 1227-1232.

22. Winter RN, Rhee JG, Kyprianou N (2004) Caspase-1 enhances the apoptotic response of prostate cancer cells to ionizing radiation. Anticancer research 24(3A): 1377-1386.

23. Wang L, Wang H, Fu G et al. (2016) Novel extracellular and nuclear caspase-1 and inflammasomes propagate inflammation and regulate gene expression: a comprehensive database mining study, Journal of hematology \& oncology 9(1): 1-18.A.F.

24. Taghiyev AF, Rokhlin OW, Glover RB (2011) Caspase-2-Based Regulation of the Androgen Receptor and Cell Cycle in the Prostate Cancer Cell Line LNCaP, Genes \& cancer 2(7): 745-752.

\section{Figures}


Figure 1

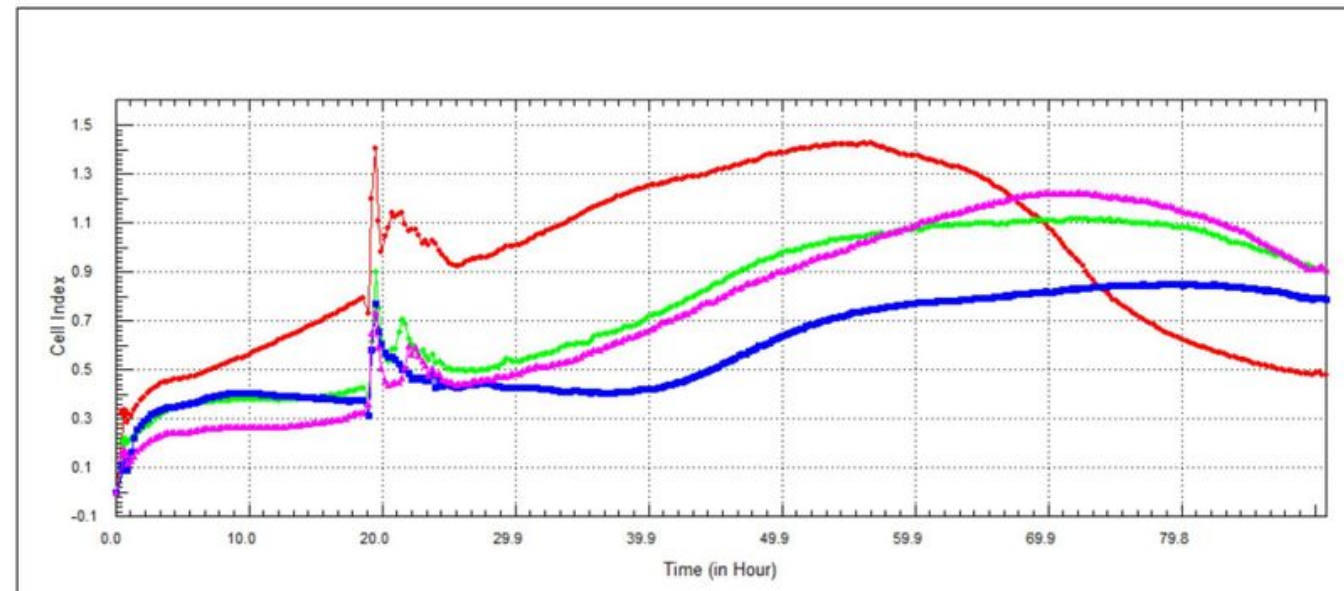

A
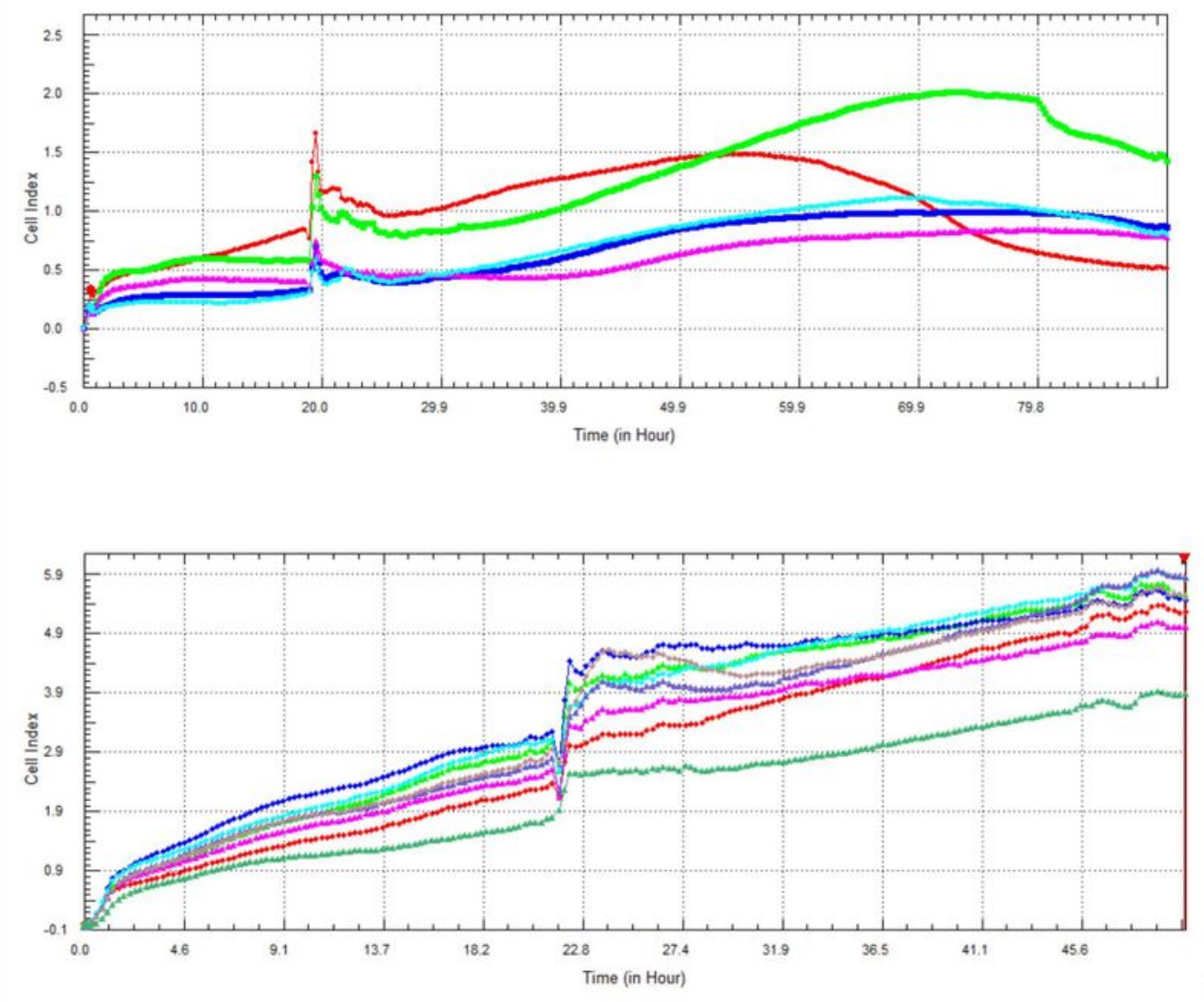

$\mathrm{C}$

\section{Figure 1}

Cytotoxic effect of VA on PC-3 cells as displayed by the RTCA xCELLligence instrument. (A) Cells incubated with different concentration of carbolitaxel (Red: Control Pink: $1 \mathrm{mg}$, Green: 5mg Blue: $10 \mathrm{mg}$ ), (B) different concentration of VA on PC-3 cell (Green: $50 \mu \mathrm{M}$, Red: $100 \mu \mathrm{M}$, Turquose: $25 \mu \mathrm{M}$, Blue: 12.5 $\mu \mathrm{M}$, Pink: $6.25 \mu \mathrm{M})$, (C) different concentration of VA on HUVEC cell (Blue: $100 \mu \mathrm{M}$, Brown: $50 \mu \mathrm{M}$, Green: $25 \mu \mathrm{M}$, Purple: $12.5 \mu \mathrm{M}$, Pink: $6.25 \mu \mathrm{M}$, Red: $3.12 \mu \mathrm{M}$, Dark green: $1.56 \mu \mathrm{M})$. 
Figure 2

A

Control

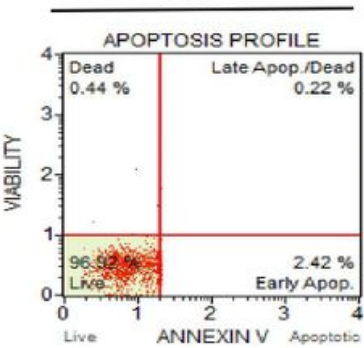

(a)
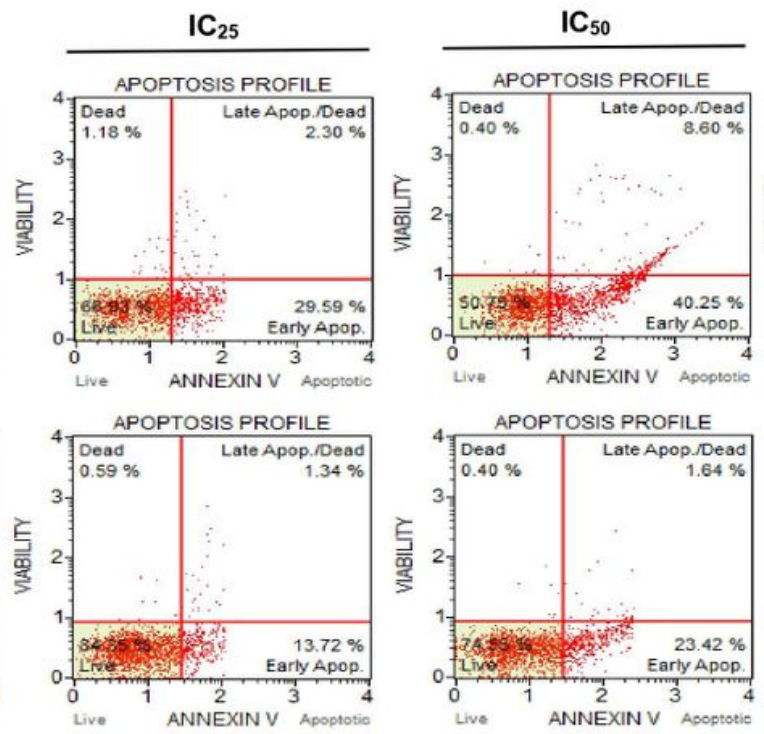
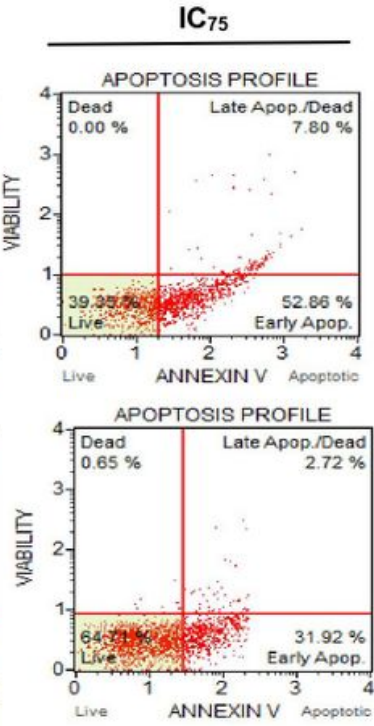

B

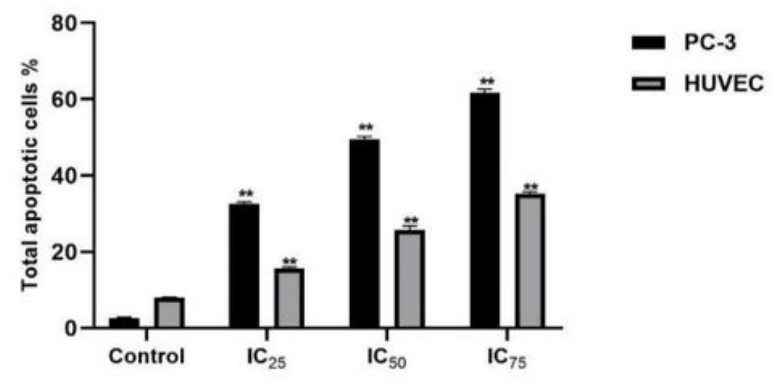

Figure 2

The evaluation of VA induced apoptotic effect by Annexin V analysis. (A) Histograms of Annexin V results in (a) PC-3 and (b) HUVEC cells. (B) Statistical comparison of the percentage of total apoptotic cells in the cells following incubation with the IC25, IC50 and IC75 value of VA for 48 h $\left(p<0.05^{\star}, p<0.01^{\star *}\right)$. 
Figure 3

A

PC-3

(a)

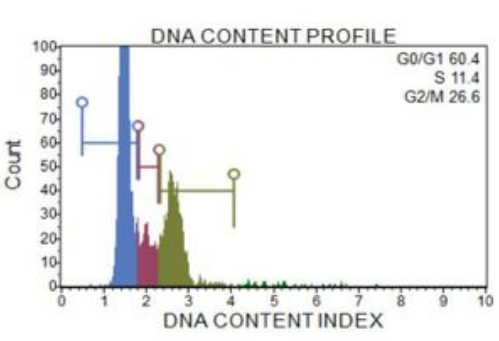

(b)

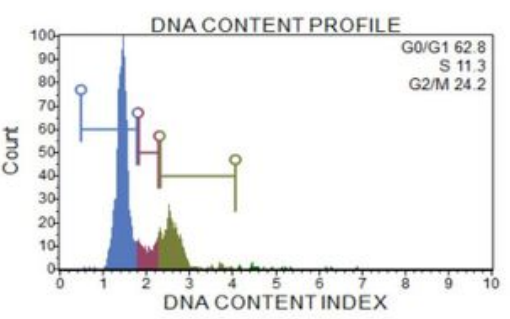

(c)

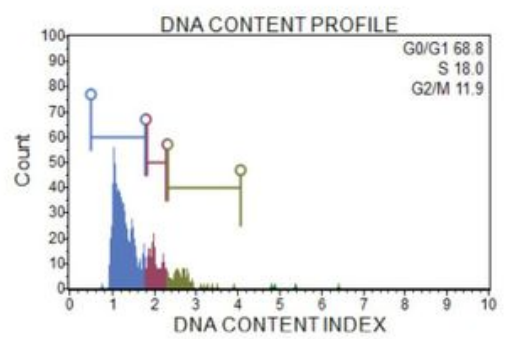

DNA CONTENT PROFILE

(d)

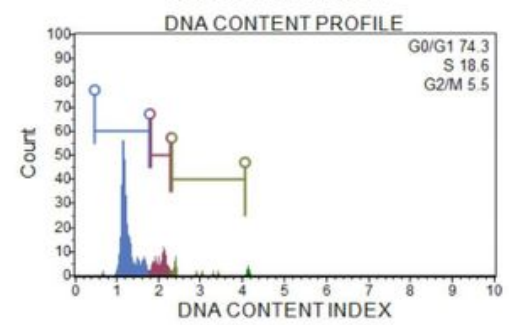

B

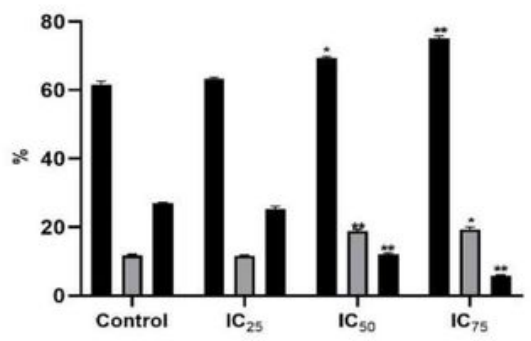

HUVEC
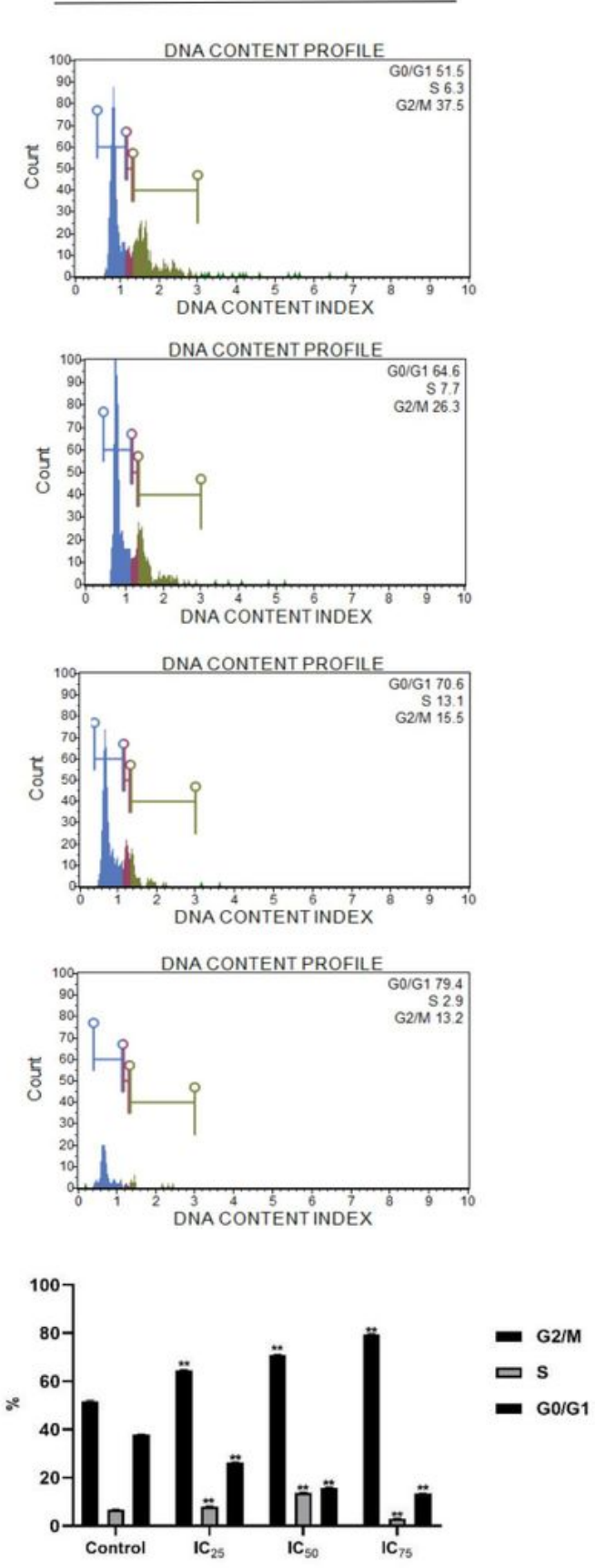

\section{Figure 3}

(A) The accumulation of PC-3 and HUVEC cells after treatment with the (b) IC25, (c) IC50 and (d) IC75 value of VA for $48 \mathrm{~h}$ compared with (a) Control. (B) Statistical comparison of the percentage of G0/G1, S and $G 2 / M$ phase arrest in the cells $\left(p<0.05^{\star}, p<0.01^{\star \star}\right)$. 


\section{Figure 4}

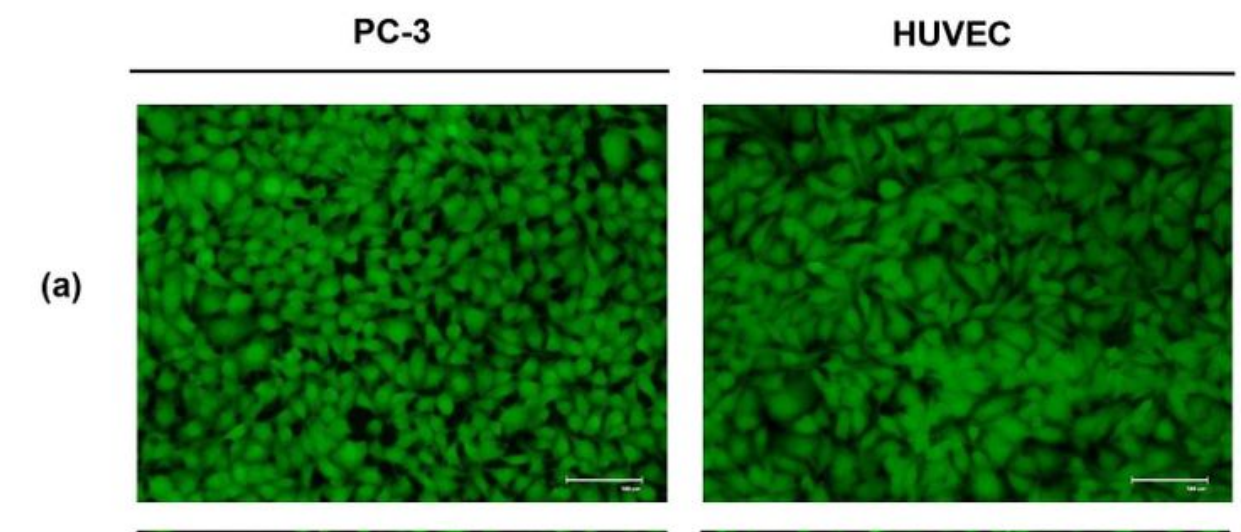

(b)
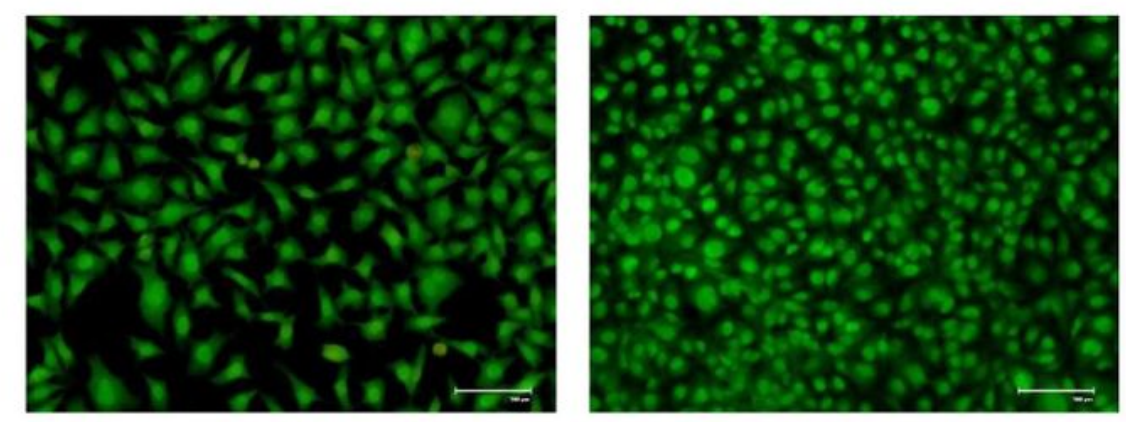

(c)
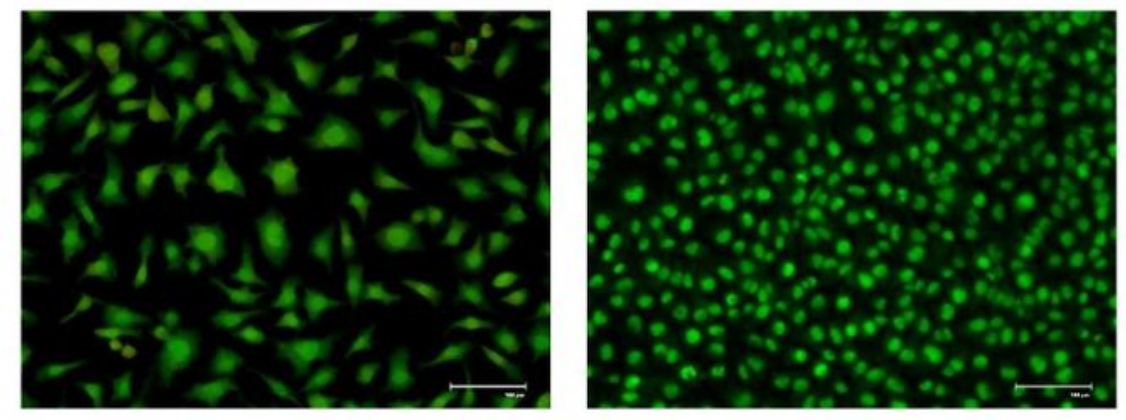

(d)
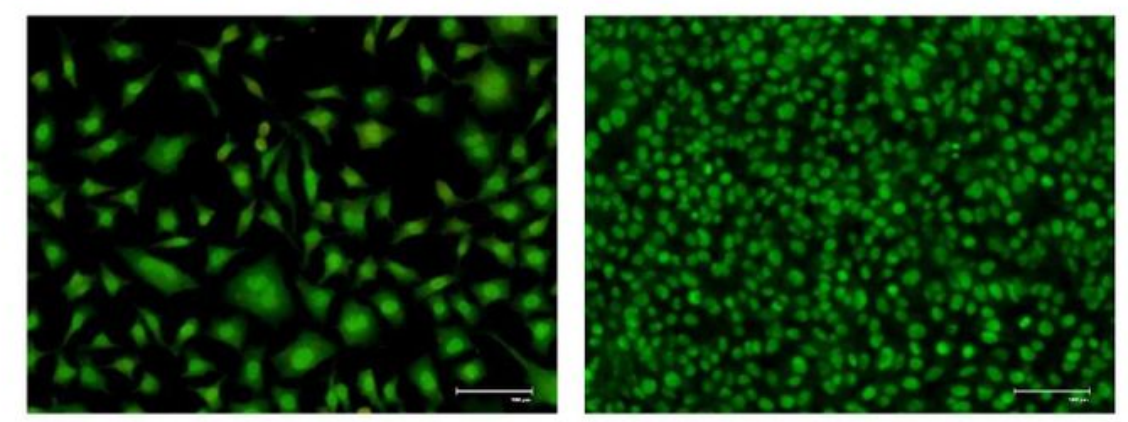

\section{Figure 4}

The morphological changes in PC-3 and HUVEC cells after treatment with the (b) IC25, (c) IC50 and (d) IC75 value of VA for $48 \mathrm{~h}$ compared with (a) Control. 
Figure 5

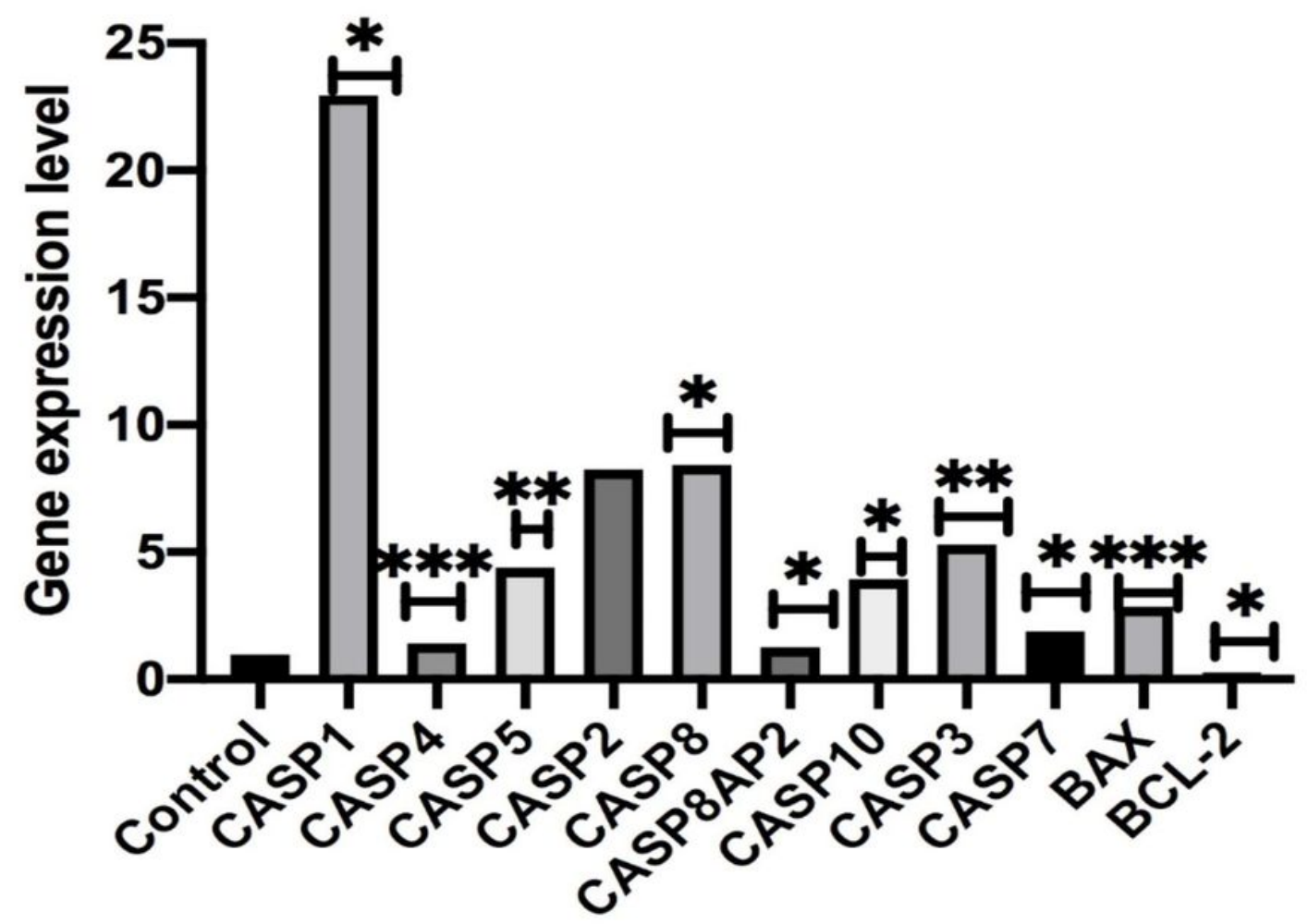

Figure 5

PC3 cells were treated with IC50 concentration of VA for $48 \mathrm{~h}$ and the qRT-PCR assay was performed. Caspase family genes, Bax and $\mathrm{Bcl}-2$ gene expression levels determined. Significantly different when compared to untreated cells $\left({ }^{\star} p<0.05,{ }^{* *} p<0.01,{ }^{* \star *} p<0.001\right)$. 